\title{
A STUDY ON PERFORMANCE OF DIFFERENT OPEN LOOP PID TUNNING TECHNIQUE FOR A LIQUID FLOW PROCESS
}

\author{
Pijush Dutta ${ }^{1}$,Dr.(Prof) Asok Kumar ${ }^{2}$ \\ Department of Electronics \&Communication Engg.,Global Institute of Management \& \\ Technolgy,India \\ Department of Electronics \&Communication Engg,,MCKV Institute of Engg.,India,
}

\begin{abstract}
Process control is the application and study of automatic control to maintain a process at the desired operating condition, safety, and efficiently while satisfying the environmental and product quality. Like the Level,Temparature \& Pressure, Liquid flow Measurement is one of the major controlling parameter in process plant. This paper mainly concern about the single tank liquid flow process and designing the controller with different PID tunning methods. Many process plants controlled by the PID controller with similar dynamics to find out the possible set of satisfactory controller parameters from the less plant information but from the mathematical model. With minimum effort adjust the controller parameters by using three open loop PID controller IMC,CHR \& AMIGOand compare their output response in real time flow tank system.
\end{abstract}

\section{Keywords}

Liquid flow System, IMC,C-H-R,AMIGO.

\section{INTRODUCTION}

In recent times the various parameters like temperature, pressure,level and flow are controlled in the process of industry.Flow rate control is one of the important parameter in a process system to keep the liquid the flow in the plant suck as oil,water,chemical liquids in tanks under control.To maintain a set point at a given value and able to accept te new set point value dynamically in the flow rate controlled system a proper controller should be designed._To meet their required performance in time response or in frequency response The conventional PID controller parameters are tuned for controlling the flow rate of the fluid [1,2]..In that the comparison of time domain and frequency domain of PID controller mentioned in this process control performance for $20 \%$ increase or decrease in the gain, time constant Dead time is determined .The best advantage of such controller scheme is that in can handle the constrained of actuated variables and internal variables. To forcast the process behaviour over the horizon of interest in most of application is [15],[16].A large number of process control show that PID controller are poorly tuned as because the PID parameters are operated non systematically .In this paper proper model designed by following steps-

Step 1.By using the proper Half rule the delay model is designed..

Step 2. Apply the model-based controller settings., 
International Journal of Information Technology, Control and Automation (IJITCA) Vol. 6, No.2, April 2016

\section{LIQUID FLOW SYSTEM}

\subsection{Brief description of liquid level System}

In the process industries the control of liquid level and flow between the tanks is a basic problem. Most of the chemical and mixing treatment of the liquid , the level must be controlled and flow between these tanks need to be regulated.In all chemical engineering system level and flow are the heart and nerve of that system .The industries where the liquid level and flow rate are the necessary parameters includes in following industries

- Petro-chemical industries.

- Paper making industries.

- Water treatment industries etc.

\subsection{Modeling of liquid level System}

According to the value of Reynolds number it is essential to divide the flow regime into laminar and turbulent flow.In case the laminar flow the Reynolds number is less than about 2000and for turbulent flow the Reynolds number is greater than about 3000to 4000.Non linear differential equation is used for the system which involve turbulent flow and for the laminar flow linear differential equation is used.In a Industrial process where the liquid flow through connection pipes and tanks is often turbulent not laminar flow. The dynamic model of the flow can be represented by introducing the concept of resistance and capacitance. The resistance $R$ is a liquid flow restriction is defined as the change in the level difference to the cause a unit change in flow rate.

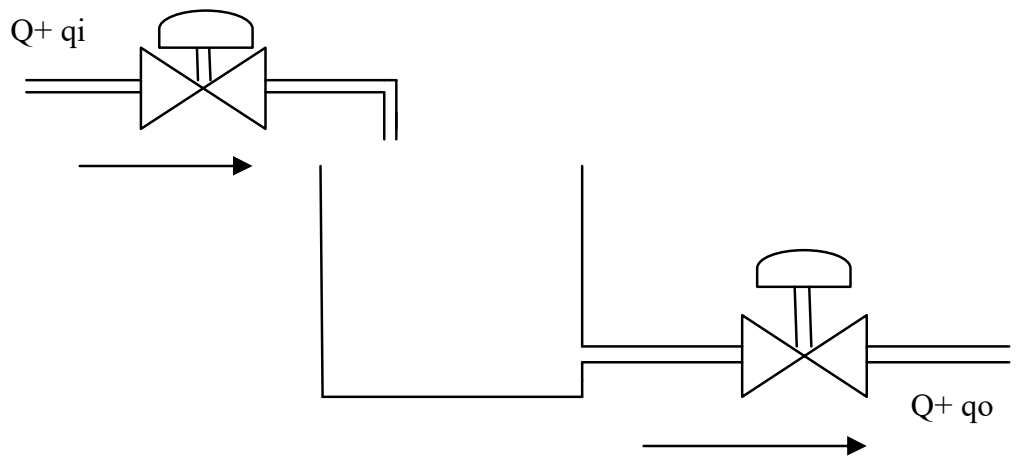

Fig.1liquid flow diagram

Consider the flow through a tanks connecting to two pipe (incoming \& outgoing). The resistance $\mathrm{R}$ for liquid flow in such a pipe is defined by the charge in the level difference which is necessary to cause a unit change in flow rate. In this system the liquid flow out through the load valve in the side of the tank. In this system the flow is laminar, hence the relationship between the steady state flow rate and steady state head at the level is given by

$\mathrm{Q}=\mathrm{KH}$

Where $\mathrm{Q}=$ Steady-state liquid flow rate,

$\mathrm{K}=$ Coefficient of proportionality, $\mathrm{H}=$ Steady-state head, 
International Journal of Information Technology, Control and Automation (IJITCA) Vol. 6, No.2, April 2016

In case of the turbulent flow, the relationship between steady state flow rate and steady state head is given by

$Q=k \sqrt{ } H$

Since, $\mathrm{dQ}=\frac{K}{2 \sqrt{H}} \mathrm{dH}$;

$\frac{d H}{d Q}=2 \frac{\sqrt{ } H}{K}$

From the equation (2) we get

$\frac{d H}{d Q}=\frac{2 H}{Q}$

Now we introduced the analogous resistance and capacitance here, to representing the turbulent flow in the system

$\mathrm{R}_{\mathrm{t}}=\frac{d H}{d Q}$
$\mathrm{R}_{\mathrm{t}}=\frac{2 H}{Q}$

The value of the turbulent flow resistance $R t$ depends upon the flow rate and head. Thus we can say that, the flow rate is defined by

$\mathrm{Q}=\frac{2 H}{R t}$

The capacitance of the liquid level system can be defined as the change in the quality of stored liquid to cause a unit change in head

$\mathrm{C}=($ change in liquid stored, $) /($ change in head $) ;$

The capacitance of the tank is equal to the cross- sectional area of it . If the liquid stored capcity is constant then the capacitance is constant for any head.

$$
\begin{aligned}
& \mathrm{Q}=\text { steady -state flow rate, } \\
& \mathrm{q} \text { i }=\text { small deviation of inflow rate from its steady-state value, } \\
& \mathrm{qo}=\text { small deviation of outflow rate from its steady-state value, } \\
& \mathrm{H}=\text { steady-state head, } \\
& \mathrm{h}=\text { small deviation of head from its steady-state value, }
\end{aligned}
$$

as stated previously, a system is said to be linear if the flow of liquid is laminar. Even if the flow is turbulent, the system can be linearized if the variables changes are kept small. The differential equations of this system can be obtained by the inflow minus outflow during the small time interval $d t$ is equal to the additional amount stored in the tank, is given by

$C d h=(q i-q o) d t$

Since, we know that

$$
\mathrm{q} i=\frac{H}{R}
$$


International Journal of Information Technology, Control and Automation (IJITCA) Vol. 6, No.2, April 2016 Equation (9) becomes

$R C \frac{d h}{d t}+h=R \mathrm{q} i$

Note that the RC is the time constant of the system. Taking Laplace transform of both sides of equation (10), by assuming zero initial conditions.

$(\mathrm{SRC}+1) \mathrm{H}(\mathrm{s})=\mathrm{RQi}$

If we consider, $q i$ is input for the system and $h$ is the output for the system, then the transfer function of the system is given by

$\frac{H(s)}{Q i(s}=\frac{R}{1+R C S}$

If the qo is taken as the output and the input is $q i$, then the transfer function of the system is given by as follows:

$$
q o=\frac{H}{R}
$$

Taking Laplace transform both the sides, we get

$\mathrm{Q}_{0}(\mathrm{~s})=\frac{H(s)}{R}$

From equation (11) and (12), we obtain

$\begin{array}{lll}\frac{Q 0(s)}{Q i(s)}= & \frac{R}{1+R} \\ \frac{Q 0(s)}{Q i(s}= & \frac{0.23}{1+7 S} \quad \text { where } \quad[\mathrm{R}=0.23, \mathrm{C}=30.4]\end{array}$

\subsection{Determination of Process Transfer Function:}

Matlab code : $\mathrm{H}=\mathrm{tf}([0.23],[7$ 1] $) ;>>$ stepplot $(\mathrm{H})$

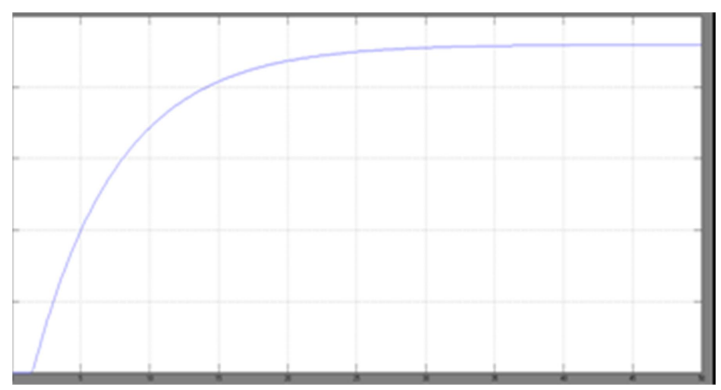

Fig 2. Time delay step response for the uncontrolled $1^{\text {st }}$ order transfer function

Time domain analysis :

Rise time : 15.4

Settling time: 27.4

$\mathrm{t} 1=3.17 \quad(35.3 \%$ of the max amp) 
International Journal of Information Technology, Control and Automation (IJITCA) Vol. 6, No.2, April 2016

$\mathrm{t} 2=12.4(85.3 \%$ of the $\max \mathrm{amp})$

$\mathrm{K}=0.229$

After computing the $\mathrm{t} 1 \& \mathrm{t} 2$ the time time delay $(=\theta)$ and the process time constant $(=\mathrm{T})$ can be obtained by the following equation $\Theta=1.3 \mathrm{t} 1-0.29 \mathrm{t} 2=0.525, \mathrm{~T}=0.67(\mathrm{t} 2-\mathrm{t} 1)=6.1841$

Now the transfer function can be represented by the equivalent first order time delay form is

$$
\begin{aligned}
\mathrm{G}(\mathrm{s}) & =\frac{K}{T s+1} \exp (-\Theta * \mathrm{~s} \\
& =\frac{0.23}{6.18 s+1} \exp (-0.525 * \mathrm{~s})
\end{aligned}
$$

\section{Tunning Methods}

\subsection{AMIGO Method:}

AMIGO (Approximate M-constrained Integral Gain Optimization) tuning method uses a different PID control algorithm compared to the previous methods. Here ltering is applied on all terms, not only on the derivative part. The AMIGO controller is given as

$u(t)=k p(b y r(t)-y f(t))+k i \int_{0}^{t} \operatorname{yr}(\alpha)-y f(\alpha) d \alpha+k d(c d y r(t) / d t-y f(t) / d t)$

where $b$ and $c$ are the set-point weights and $y(f)$ is the ltered process output signal. $Y(f)$ is obtained from the process output signal y by ltering, i.e. Yf (s) = Gf (s)Y (s). The lter transfer function is

$\mathrm{Gf}(\mathrm{s})=1 /\left(1+\mathrm{s} \mathrm{T}_{\mathrm{f}}\right)^{\mathrm{n}}$

where $\mathrm{T}_{\mathrm{f}}$ is the time constant and $\mathrm{n}=1,2, .$. is the order. The AMIGO PID controller actually has six tunable parameters kp, ki , kd, Tf, b and c. The AMIGO tuning rules proposed by Åström and Hägglund in [8] are

$\mathrm{Kp}=1 / \mathrm{K}(0.2+0.45 \mathrm{~T} / \mathrm{L} 1) ; \mathrm{Ti}=\mathrm{L} 1(0.4 \mathrm{~L} 1+0.8 \mathrm{~T}) /(\mathrm{L} 1+0.1 \mathrm{~T}) ;$

$\mathrm{Td}=0.5 \mathrm{~L} 1 \mathrm{~T} /(0.3 \mathrm{~L} 1+\mathrm{T})$

where parameters K, T and L1 are determined by the rst order model in(14) Filter time constant is set to $\mathrm{Tf} \approx 0.1 \mathrm{~L} 1$ and the set point weights are set to $\mathrm{c}=0$ and

$\mathrm{b}=0$, if $\mathrm{L} 1 \mathrm{~T}+\mathrm{L} 1<0.5$

1 , if $\mathrm{L} 1 \mathrm{~T}+\mathrm{L} 1 \geq 0.5$

Note that $\mathrm{kp}=\mathrm{Kp}, \mathrm{ki}=\mathrm{Kp} / \mathrm{Ti}$ and $\mathrm{kd}=\mathrm{KpTd}$.

\subsection{IMC Method :}

The internal model controller provides a transparent frame work for control system design and tuning. The first order transfer function of the process has been adopted as a reference $[3,6]$. The derivation to calculate the parameters of ideal internal model control based proportional integral derivative controller is expressed in below.

$\mathrm{Gp}(\mathrm{s})=\mathrm{kp} /(\tau \mathrm{ps}+1)$

$\mathrm{Gp}(\mathrm{s})$ is the transfer function of the process 
International Journal of Information Technology, Control and Automation (IJITCA) Vol. 6, No.2, April 2016

$\mathrm{Gp}(\mathrm{s})=0.23 /(7 \mathrm{~s}+1)$

The ideal internal model control controller transfer function $\mathrm{Q}(\mathrm{s})$ which includes the filter $\mathrm{f}(\mathrm{s})$ to make a $\mathrm{Q}(\mathrm{s})$ semi proper is given below

$\mathrm{Q}(\mathrm{s})=\mathrm{Gp}-1(\mathrm{~s}) \mathrm{f}(\mathrm{s})$

$\mathrm{f}(\mathrm{s})=1 /(\lambda \mathrm{s}+1)$

$\mathrm{Q}(\mathrm{s})=((7 \mathrm{~s}+1) / 0.23) *(1 / \lambda \mathrm{s}+1)$

$\lambda$ is the tuning parameter of the filter $\mathrm{f}(\mathrm{s})$

Take the value of $\lambda$ as $0.466[=7 /(3 * 5)]$, which is practically one third of one fifth of time constant and put it in equation (4.6) to get the value of ideal internal model control controller $\mathrm{Q}(\mathrm{s})$. The equation becomes

$\mathrm{Q}(\mathrm{s})=((7 \mathrm{~s}+1) / 0.23) *(1 / 0.466 \mathrm{~s}+1)$

$\mathrm{Q}(\mathrm{s})=(7 \mathrm{~s}+1) /(0.107 \mathrm{~s}+0.23)$

From the above equation (4.6), the value for the proportional integral tuning parameters is given by

$\mathrm{kc}=\tau \mathrm{p} / \mathrm{kp} \lambda$

$\mathrm{kc}=7 / 0.23 * 0.466=65.31$

$\tau \mathrm{i}=\tau \mathrm{p}=7$

So the transfer function of proportional integral controller is now given by $\mathrm{Gc}(\mathrm{s})=\mathrm{kc}((\tau$ is +1$) /$ ( is $)$

$\mathrm{Gc}(\mathrm{s})=65.31((7 \mathrm{~s}+1) /(7 \mathrm{~s}))$

The above transfer function without delay and disturbance results in proportional integral control only.

\subsection{C-H-R Method :( Chien ,Hrones and Reswick)}

In the process industry the parameters are often tuned according to CHR recommendations . They are based on the tuned parameters of open loop step reference change response. This type PID tuning method is only useful for the $0 \%$ overshoot.

\section{Simulation \&Analysis \\ 4.1.PID Controller response :}

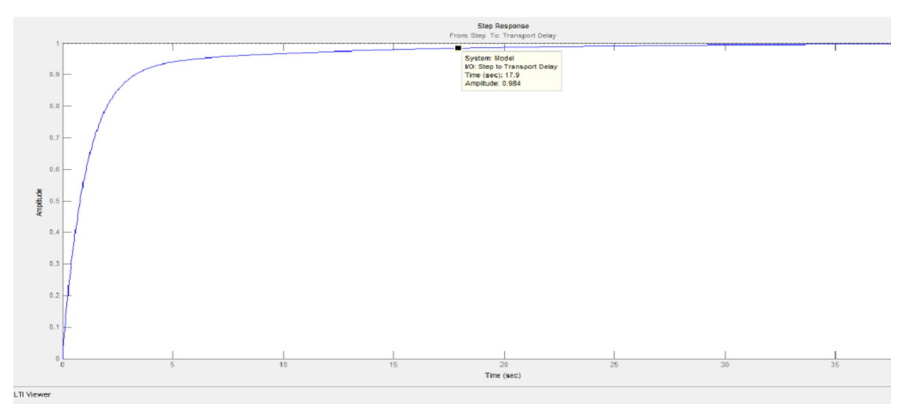

Fig3.AMIGO PID step response 
International Journal of Information Technology, Control and Automation (IJITCA) Vol. 6, No.2, April 2016

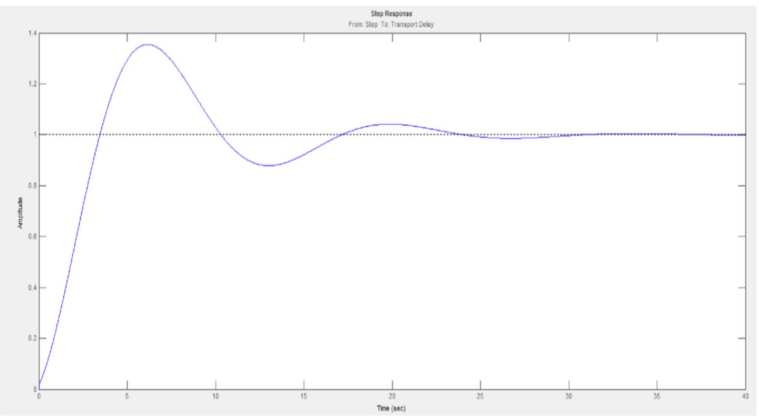

Fig4. IMC PID step response

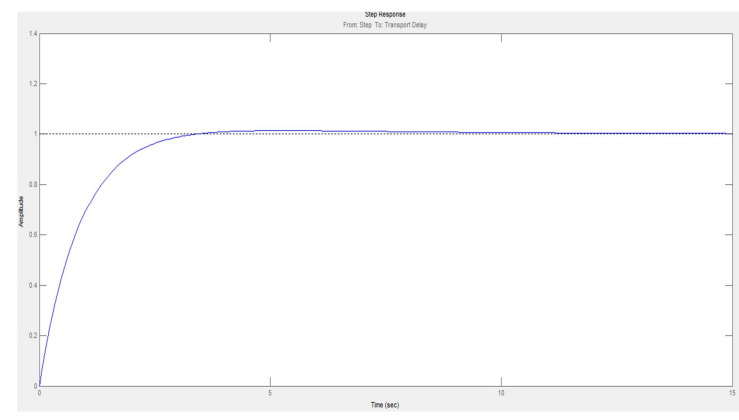

Fig5.CHR PID step response

\subsection{Bode Plot characteristics :}

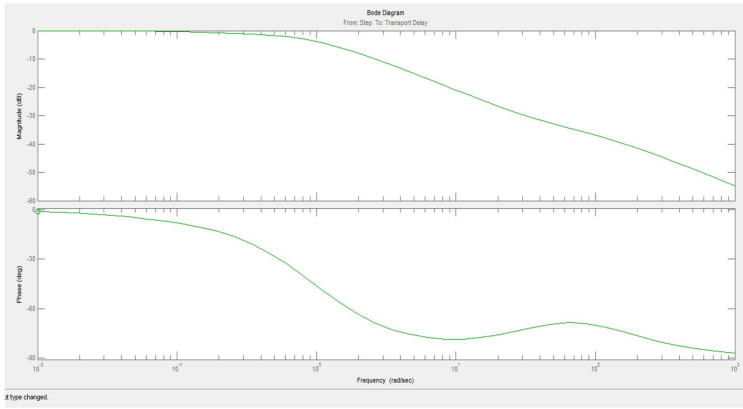

Fig6.Bode plot for AMIGO PID tunning

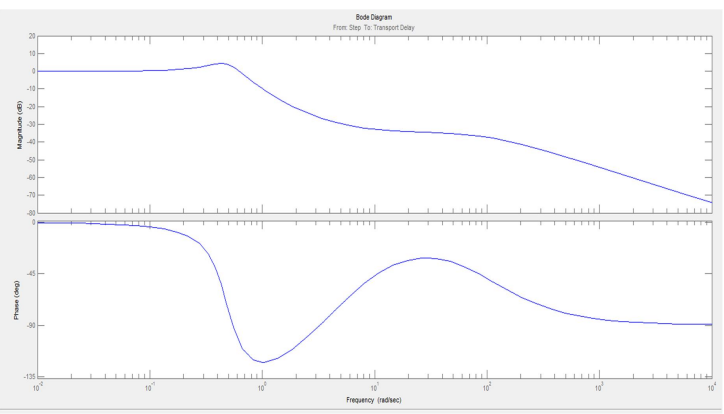

Fig7.Bode plot for IMC PID tunning 
International Journal of Information Technology, Control and Automation (IJITCA) Vol. 6, No.2, April 2016

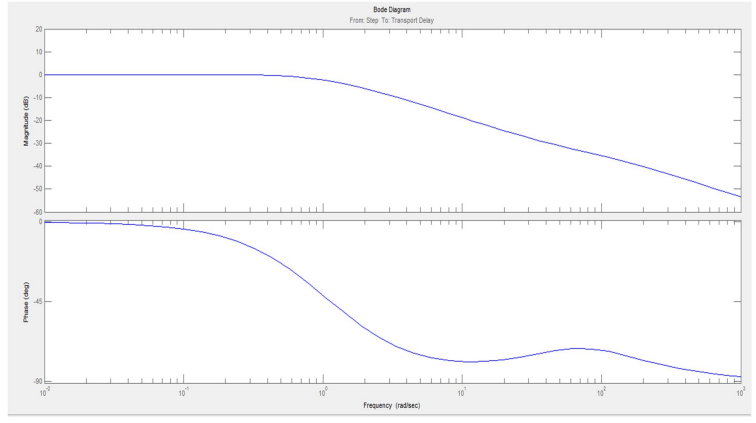

Fig7.Bode plot for C-H-R PID tunning

\section{C Nyquist characteristics :}

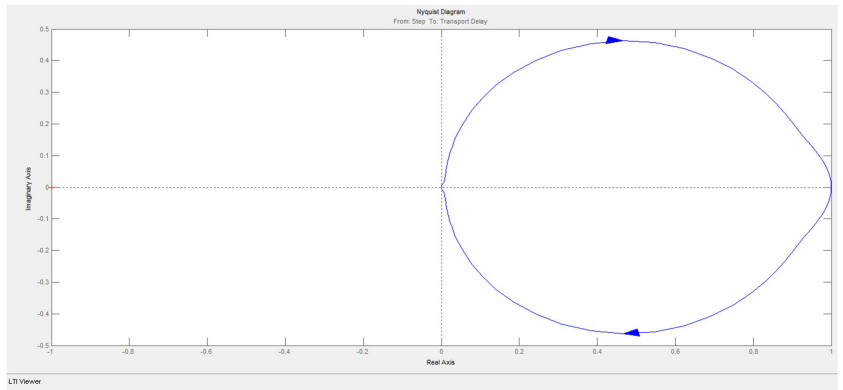

Fig8.Nyquist plot for AMIGO PID tunning method

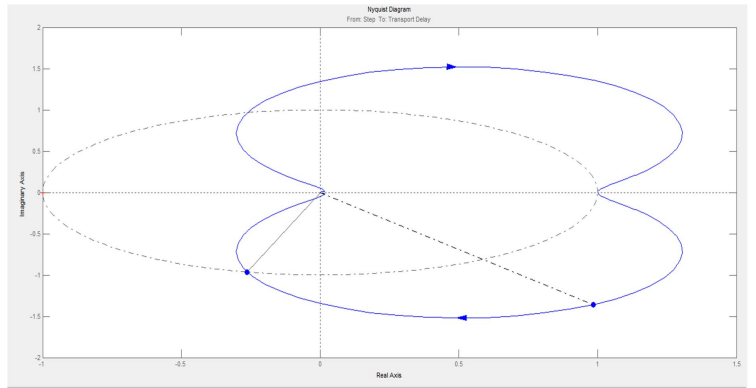

Fig9. Nyquist plot for IMC PID tunning method

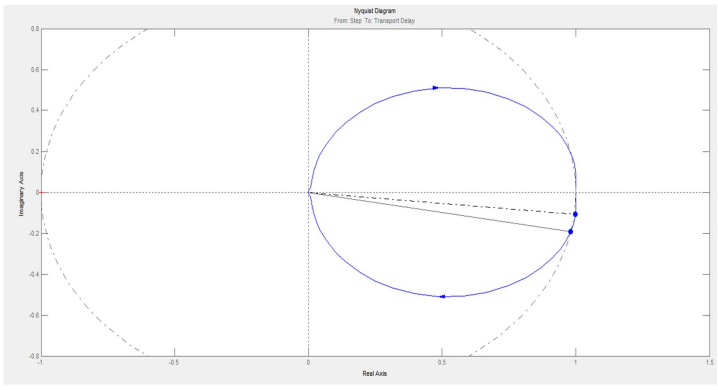

Fig10. Nyquist plot for C-H-R PID tunning method 
International Journal of Information Technology, Control and Automation (IJITCA) Vol. 6, No.2, April 2016

TABLE1.Open loop pid tunning parameters

\begin{tabular}{|c|c|c|c|}
\hline Method & $\mathrm{Kp}$ & $\mathrm{Ti}$ & $\mathrm{Td}$ \\
\hline AMIGO method & 24.02 & 2.36 & 0.2559 \\
\hline $\begin{array}{c}\text { IMC method } \\
(\lambda=0.13125)\end{array}$ & 4.230 & 6.4466 & 0.4831 \\
\hline C.H.R method & 30.8626 & 6.1841 & 0.2625 \\
\hline
\end{tabular}

TABLE2.Time domain analysis for different tunning method

\begin{tabular}{|c|c|c|c|c|}
\hline Method & Rise time & Peak time & Settling time & overshoot \\
\hline AMIGO method & 2.03 & 27.5 & 17.9 & no \\
\hline $\begin{array}{c}\text { IMC method } \\
(\lambda=0.13125)\end{array}$ & 4.6 & 6.07 & 15.5 & no \\
\hline C.H.R method & 1.94 & 6.1 & 11.9 & $10 \%$ \\
\hline
\end{tabular}

TABLE3.Frequency domain \& robustness analysis

\begin{tabular}{|c|c|c|c|c|}
\hline \multirow{2}{*}{ Method } & \multicolumn{2}{|c|}{ Frequency domain analysis } & \multicolumn{2}{c|}{ robustness analysis } \\
\cline { 2 - 5 } & Gain margin & Phase margin & $\begin{array}{c}\text { Modulus } \\
\text { margin }(\mathrm{db})\end{array}$ & $\begin{array}{c}\text { Dealy margin } \\
(\mathrm{sec})\end{array}$ \\
\hline $\begin{array}{c}\text { AMIGO } \\
\text { method }\end{array}$ & infinite & -6.26 & -61.3633 & 3.0587 \\
\hline $\begin{array}{c}\text { IMC } \\
\text { method } \\
(\lambda=0.13125)\end{array}$ & Infinite & -0.578 & -39.1834 & 1.0161 \\
\hline $\begin{array}{c}\text { C.H.R } \\
\text { method }\end{array}$ & Infinite & -0.657 & -54.8578 & 1.5114 \\
\hline
\end{tabular}

\section{CONCLUSIONS}

For,the open loop liquid flow tunning method gives $0 \%$ overshoot except the CHR method as shown in figure as well as the table2.The IMC \&CHR gives the least settling time but AMIGO \& CHR gives least rise time.Show out of all open loop tunning method IMC \& CHR tunning methods gives the best performance while time domain analysis AMIGO tunning method gives the least saisfactory performance in liquid flow process.In a frequency domain analysis only IMC open loop method gives the value of the phase margin within the range but the gain margin is not achieved.In robustness analysis modulus margin \& delay margin both are not fall in range. In a nyquist plot no one of the open loop tunning system enclosed the point $-1+\mathrm{j} .0$.

\section{REFERENCES}

[1] Niimura, T. and Yokoyama, R., "Water level control of small-scale hydro- generating units by fuzzy logic", Proceedings of IEEE International Conference on Systems, Man and Cybernetics, pp. $483,1995$.

[2] Roubos,J.A., Babuska,R., Bruijn,R.M. and Verbruggen,H.B., "Predictive Control by Local Linearizatin of a Takagi-Sugeno Fuzzy Model”, IEEE Transactions, 1998.

[3] N.K Bose, P. Liang, "Neural network fundamentals with graphs, algorithms and applications",2001.

[4] Ghwanmeh,S.H., Jones,K.O. and Williams,D., "On-line Performance Evaluation of a Self- Learning Fuzzy Logic Controller Applied to Non-Linear Processes”, IEEE Transactions, 1996 
International Journal of Information Technology, Control and Automation (IJITCA) Vol. 6, No.2, April 2016

[5] Riyaz Shariff, Audrey Cudrak and Qing Zhang "Advanced process control techniques for water treatment using artificial neural networks"

[6] J. Environ. Eng. Sci. 3(S1): S61-S67 (2004).[6] Xiao,Y., Hu,H., Jiang,H., Zhou,J.and Yang,Q., “A Adaptive Control Based Neural Network for Liquid Level of Molten Steel Smelting Noncrystlloid Flimsy Alloy Line", Proc. of 4th World Congress on Intelligent Control and Automation, China, 2002.

[7] Yamada, T.and Yabuta, T., "Dynamic system identification using neural networks", Systems, Man and Cybernetics, IEEE Transactions on,Vol.23, Issue 1,Jan/Feb, 1993.

[8] S. Haykin, Neural Networks: "A comprehensive foundation", 2002.

[9] Narendra, K.S. and Parthasarathy, K., "Identification and Control of Dynamical Systems Using Neural Networks”, Neural Networks, IEEE Transactions on,Vol.1, No.1,Mar,1990.

[10] Takagi,T. and Sugeno,M., "Fuzzy Identification of System and its Applicaiton to Modeling and Control", IEEE Transactions on Systems, Man and Cybernetics, Vol.15, No.1, 1985.

[11] D. W. Clarke, C. Mohtadi, and P. S. Tuffs, "Generalized predictivecontrol-part 1: The basic algorithm," Automatica, 137-148 vol.23, 1987.

[12] Tan, K.K., Lee, T.H., Hunag, S.N. \& Leu, F.M., "PID control designbased on a gpc approach," Industrial \& Engineering Chemistry Research 41(8), 2002.

[13] T. Peterson. E. Hemandez. Y. Arkun, and F.J. Schork, "Nonlinear Predictive Control of a Semi Batch Polymerisation Reactor by an Extended DMC." Proc. I989 American Control Conference, pp. 1534- 1539. in 1989.

[14] J. Thibault and B.P.A. Grandjean. "Neural Networks in Process Control:A Survey," Advunced Control of Chemical Processes. K. Najim and E.Dufour. eds.. IFAC Symposium Series No. 8, pp. 251.260.

[15] C. Cutler and B. Ramaker, "Dynamic Matrix Control: A Computer Control Algorithm," Pror. 1980 Joint Autoniatic Coritrol Conference.

[16] C.E. Garcia and M. Morari, "Internal Model Control. I . A Unifying Review and Some New Results," hid. Eng. Chem. Process Des. Dei: 2 1.pp.308-323, 1982

[17] Katsuhiko Ogata, "Modern Control System", 3rd edition, Prentice Hall, Upper Saddle River, New Jersy 07458

\section{Authors:}

Pijush Dutta :He received the Bachelor's Degree in the Department of Electronics \& communication Engneering Dept.\& Masters Degree in the Department of Mechatronics from West Bengal University of Technology, India, in 2007 and 2012 respectively.He is currently assistant professor in the department of ECE Department, in Global Institute of Mangement Technology, Krishnagar ,India. His research are is intelligence system $\&$,sensor \& transducer .

Dr(Prof)Asok Kumar:He received the Bachelor \&Masters in the Department of Radio Physics \&electronics from Calcutta University ,India in 1997\&1999repectively .He received His Phd Degree from Jadavpur university from 2007.He has more than 45 international \& national journal .His research fields are coding,communication .sensor \&Transducer \& intelligence system .
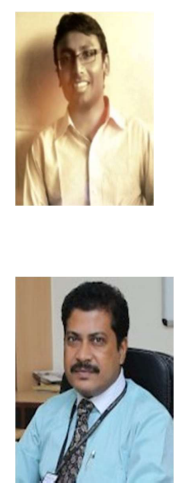